\title{
Suitability of Multiple-choice Questions in Evaluating the Objectives of Academic Educational Process of Accounting Specialization
}

\author{
Naser Yousef ALzoubi ${ }^{1}$, Asma Shafe Assaf ${ }^{2}$ \\ ${ }^{1}$ Irbid National University, Jordan \\ ${ }^{2}$ Higher Colleges of Technology, Sharjah, UAE \\ Correspondence: Naser Yousef ALzoubi, Associate Professor in Accounting, Irbid National University, Jordan.
}

Received: April 1, 2017

doi:10.5539/ibr.v10n6p46
Accepted: May 2, 2017

Online Published: May 4, 2017

URL: https://doi.org/10.5539/ibr.v10n6p46

\begin{abstract}
This study attempt to investigate and explore the use of multiple-choice questions (MCQs) at Jordanian public and private universities, from the point view of faculty member who are teaching accounting specialization and use MCQs in examinations of accountancy subjects. The study seeks to identify the extent MCQs can achieve regarding level of knowledge among students, assess the deep understanding and In-depth learning to measure and evaluate the range of learning in subjects of accounting specialization. To achieve the objectives of the study, a questionnaire designed according to the requirements of Ministry of Education in Jordan and the International Accounting Education Standard Board (IAESB).Based on analyzing responses and examining hypotheses, results clarify that MCQs are not enough tools to achieve the educational objectives concerning accounting subjects, in both theoretically and practically aspects. It was clear that there are no significant differences between the opinions of faculty members, neither public nor private universities. The study recommends that there is a need to re-consider the use of MCQs as a tool to evaluate the students' abilities and skills in subjects of accounting specialization.
\end{abstract}

Keywords: multiple-choice questions, accounting education, accounting exams

\section{Introduction}

\subsection{Introduce the Problem}

Recently, It is very obvious that faculty members at Jordanian universities adopting significantly MCQs in university exams as a tool to evaluate the educational process. MCQs being used almost on a large scale in all academic fields, taking into consideration that accounting subjects basically a practical major that relies on practical and theoretical framework aspects as a field of social science based on theory and philosophy.

The statement of problem of this study identifies the ability and suitability of MCQs to achieve goals of education of accounting specialization at Jordanian universities, both practical and theoretical aspects.

It is well known that each type of tests has its advantages and disadvantages, as of multiple-choice test have its own feature of educational assessment, and educational references in general determined the foundations for selection of successful test type to be convenient for assessment of student's abilities and skills.

Problem of the study is stated in the following question:

Can MCQs achieve the educational objectives of accounting subjects at Jordanian universities in general, both theoretical and practical aspects?

This question is divided into the following two sub questions:

i. Can multiple-choice questions achieve the educational objectives of accounting subjects concerning the theoretical aspect?

ii. Can multiple-choice questions achieve the educational objectives of accounting subjects concerning the practical aspect?

\subsection{Explore Importance of the Problem}

Multiple choice questions (MCQs) are used to examine university students in order to insure that the educational 
objectives are achieved, regardless of method used whether MCQs, open book or oral questions. The use of any of these methods aims to make sure that the purpose of educational process has been achieved and to be certain that students have acquired knowledge and deep understanding of the contents of subjects which have been taught.

The choice of test method is an absolute unrestraint to the instructor, but the purpose and the appropriateness of the test method considered important indicators in comparison between the types of available tests, as there are many types of tests such as essay and objective questions which are related to a different advantages and disadvantages of each method to conduct a measurement, evaluation and assessment of the educational process.

The aim of current study is to focus on the most common types of questions in accounting specialization, which is the MCQs; it's widely used in professional examinations such as Certified Public Accountant (CPA) and Certified Managerial Accountant (CMA) and others. Recently, this type of questions widely used in university tests (Zucker, 2003).

It is worthy mentioned that there is a distinction between the concept of learning and the concept of education or teaching of accounting, the latter concept is the focus of this study, while the concept of learning is concerned to change or modify relatively constant behavior through training and the student's role here is an initiator and the Instructor is a coordinator, the teaching or education specifically is disciplined and oriented process, including three basic operations as follows:

i. Design process and planning whereby the input of teaching is organized in the form of syllabus to achieve the specific objectives of the educational process.

ii. The implementation process and the actual application of the plan during the semester.

iii. Assessment process, the achievement level of teaching system objectives can be met and evaluated (Zaytoun, 2001).

In regards of accounting specialization, the International Accounting Education Standard Board (IAESB) issued a set of eight international standards for the education of accounting -International Education Standard (IES) which concerns with learning and teaching the accounting subjects, the international standard for Accounting education 3IES \# "measuring the capacity and professionalism to help professional organizations in assessment, development and management of the written tests, which contains the guiding principles for the measurement and evaluation process (www.ifac.org).

The importance of this study is related to the academic and educational field at Jordanian universities and clarifies the effect of MCQs with regard to the level of educational outcomes of graduates, and importance of the study can be summarized in the following points:

i. Verify the outputs of the educational process for the students of accounting regarding information and skills they acquired in their field of specialization.

ii. Verify the validity of marks obtained by the student based on is compatible with the volume of useful information and skills received by student.

iii. Verifying the reliability of results based on MCQs and appropriateness of selected questions in assessment of student performance.

\subsection{Study Objectives}

The study aims to:

1. Evaluate the use of MCQs to assure achieving the educational objectives concerning accounting subjects in Jordanian universities in general, regarding both theoretical and practical aspects.

2. Evaluate the use of MCQs are suitable to assure the ability in achieving the educational objectives related to the theoretical aspects in accounting subjects.

3. Evaluate the use of MCQs are suitable to assure the ability in achieving the educational objectives related to the practical aspects in accounting subjects.

\subsection{Limitations of the Study}

In view of the study features and for the purpose to obtain accurate and reliable results, the study focuses were mainly on the followings:

i. Emphasis in Education and academic teaching, but did not address learning and vocational training. 
ii. University education of bachelors degree only, and did not deal with education of pre graduation or post graduates stages such as $\mathrm{MA}$ and $\mathrm{PhD}$.

iii. University education of accounting specialization, and did not address the other academic fields.

iv. Accounting subjects that are taught within the syllabus of accounting specialization, but did not addressnon-accounting subjects that are taught within the syllabus of accounting specialization.

\subsection{Describe Relevant Scholarship}

The use of MCQs style repeatedly in university education makes many researchers in the field of education in general and university education in particular, to consider the possibility of using MCQs in evaluating and achieving educational goals, several numbers of individuals of different academic fields including specialists in the universities work field have touched and addressed this matter, including a study of (Tsul, Lau \& Fong, 1995) which used the cognitive style test on students and its impact on their skills in handling and solving issues related to MCQs with the mysterious content which related to financial accounting subject, a classification of students was donebased on previous classification of a study prepared by (Witkin, Moor, Goodenough, \& Cox, 1977)which identified the variables of cognitive style of students that associated with individual differences of students and what distinguishes students from each other in terms of being aware of the information, methods and strategies that student adopted to receive knowledge and how to deal with arewhat distinguishes the response of each student as a way of thinking, Witkin has classified cognitive style to two dimensions (independent and dependent), the first dimension is an independent style, a type of students aware of the partsseparately from the cognitive domain, and thus they have a greater capacity of analysis and sensual perception when they analyze the problems they face, as the second dimension is the cognitive style based on domain, a type realizes parts based on the cognitive domain, therefore, they are not being able to deal with the stimuli or problems independently, but rely on the cognitive domain obligatory and typically as they have a low awareness of sensory. The study found that the cognitive domain of individuals have a major impact on the results, students who have an independent cognitive domain achieved more marks than students who are classified as those with dependent cognitive pattern. This was pointed out by (Gul, Teoh, \& Shannon 1992) When the workers of the teaching field use a MCQs style have to conduct their assessment of the questions accurately. The results and performance of the students don't depend on their knowledge and scientific abilities only, but also, on the differences of cognitive style of each student, therefore, attention should be paid to students with dependent cognitive pattern on the cognitive domain in order for them to be treated evenly.

Study conducted by Laffittee (1984) has noted, that in the case MCQs which starts with the simple questions and then access to the most difficult questions is building confidence among the students and thus better results in exams. The study of Balch (1989) results indicated that the students achievements would be better if the order of questions of MCQs were arranged in sequence and is identical to the sequence of scientific subject that has been taught, and the opposite would be if they were randomly ask questions of scientific subject and this was referred to the sequence of questions in order Scientific subject that may provide signal to recover the information which helps memory recall. The use of MCQs widely referred to be more acceptable to both parties lecturer and student and this is what noted by Kuechler and Simkin (2003) study whereas, the use of MCQs facilitates the examination process, if a large number of students was involved, as well as limit the deceiving attempts of students by using more than a form of questions, whether by using different questions for each model or arranged the questions differently for each model, as the exam is executed relatively ina short period of time. Both researchers tried to test and evaluate the level of understanding and assimilation of scientific subject for students in case is relied on MCQs and the final conclusion isthat this type of questions is not enough at all to measure the level of understanding and comprehension of the students, but at the same time they confirmed that most of the educational and professional institutions relied on MCQs, taking into consideration the availability of possibilities and financial resources in light of increase the number of students and teaching load on lecturers, the most favorable result is to rely on MCQs, in spite of they do not reach the level to measure and evaluate the level of understanding of the student, while the use of essay questions are more appropriate to evaluate and measure the level of understanding of the student and that were defined as (Constructed-response questions) in the sense that a student has to initiate and establish the answer clearlyinstead of depending on choosing the correct answer from the multiple alternatives for each question, also a study of Bridgeman and Lewis (1994) noted that the built exam on MCQs make lecturer capableof wider scope coverage of scientific subject and more from the use of essay questions.

Many studies have addressed the measurement of the ability of MCQs on the level of knowledge among students and assess the deep understanding they have with regard to the scientific subject that has been taught, and that's 
what (Stupans, 2006) study tried to verify the possibility of checking the level of awareness of educational subject for students, whether use of MCQs style adopted, the results showed that if lecturer wishes in assessing the scope of student's understanding of basic scientific subject (Application of Knowledge), the use of essay questions that require analysis and assembly to reach the right solution is the best to assess the level of knowledge of the student.

The study of Buckles and Siegfried (2006) was conducted to examine the possibility of In-Depth learning evaluation for the scientific subject of the students by using the MCQs, eventually, the researchers found that it is possible to benefit from the use of MCQs in public matters related to the educational subject, and if the questions were prepared precisely and carefully then it is possible that some aspects can be assessed, but not all the necessary elements that related to deep understanding of the students, it has also been noted that the test (Bloom) to measure the understanding and analysis or questions that require combination and assembly can not be measured accurately by using the MCQs only, both researchers concluded that MCQs style is helpful if it is used to test general information related to the educational subject, it is preferred to use bank of MCQs for each teaching course, but only if prepared accurately, deep, quality and proven high-quality in advance which may help lecturers in the evaluation and examination of deep understanding of the education subject of the students. The study of (Ali, Carr, \&Ruit, 2016) concluded that multiple-choice exam allows learners to detect areas of needed improvement, and instructors to encourage deep, rather than superficial, learning strategies. Other study of (Bible, Simkin, \& Kuechler, 2007) have focused on the results of (238) students concerning the Intermediate Accounting subject after conducting their exams by using the essay answers style and MCQs style, the researchers concluded that the use of MCQs could be appropriate tool to assess the level of (Subject Mastery) of the student for the educational subject, but at the same time, the study noted that there are a limitations for the fact that the study adopted Intermediate Accounting only and neglected the rest of the major subjects, and therefore, researchers have pointed out the need to conduct additional and extensive studies before granting dependence on the results of their study.

In a similar study by Kim et al, (2009) researchers conducted a comparison among students answers for the same exams questions as long as students answers on each question in two way-style, firstly, essay answer (narrative) secondly, the MCQs style after analyzing and comparing the students answers, researchers found that the essay questions facilitate the evaluation of deep understanding (In-depth Understanding) with learning subject of the student, as for the students answers with MCQs style has enabled them to achieve good marks but without the possibility of stimulating or exciting or building practical thinking (Thought Processes) for the educational subject.

The current research focused in investigating the ability of MCQs style to measure and evaluates the range of learning and deep understanding of an educational subject within accounting specialty students at Jordanian universities. This is what the most of previous studies dealt with as an attempt to ensure that the use of multiple-choice questions style test method is an access to the desire educational objectives, both aspects (Tsul et al, 1995; Bible et al, 2007) have been focused in studying the results of the students in accounting specialty for more than one semester or comparing students' results in tests after the application of MCQs and essay style at the same time and for the same sample students.

The current study characterized and distinguished from the aforementioned studies for being mainly headed for teachers or lecturers as an attempt to find out their opinions about the possibility of assessing the quantity of learning and deep understanding of educational subject of students, relying on MCQs style in a large scale, as our study covered all accounting specialty courses that are taught at Jordanian universities specifically.

\subsection{State Hypotheses and Their Correspondence to Research Design}

Based on the problem statement of the study and objectives, the study relied on the following assumptions:

H01: Multiple-choice questions do not significantly ensure to achieve the educational objectives of accounting subjects in general, both practical and theoretical aspects.

H02: Multiple-choice questions do not significantly ensure to achieve the educational objectives of accounting subjects, theoretical aspect.

H03: Multiple-choice questions do not significantly ensure to achieve the educational objectives of accounting subjects, practical aspect.

H04: There are no statistically-significant differences between the faculty members of private and public uni versities in their assessment of suitability of multiple-choice questions to achieve the educational objectives of accounting subjects, theoretical and practical aspects 


\section{Method}

\subsection{Research Design}

A questionnaire was designed to reflect the subject of the study and its objectives by reviewing literature and previous studies in connection with the subject study, it was mainly relied on the instructions related to the knowledge field of accounting specialization, based on the law and general instructions issued by Ministry of Education in Jordan, and educational goals issued by the (AICPA).

The following steps were followed in designing the questionnaire:

First:

Determine the accounting subjects that will be studied and adopted in the identified instructions and standards of the provision of the majors of Management Science "issued under paragraphs (A) and (K) of Article (7) of the law Commission of the (Accreditation and Quality Assurance Commission for Higher Education Institutions [HEAC], 2007), No. (20) And amendment No. (2010/5/32)Dated (18/2/2010) (www.heac.org.jo) for the accounting specialization, which identified the basic compulsory fields - the field of knowledge in the following subjects:

- Financial Accounting: Accounting Principles (1) - Accounting Principles (2) - Intermediate Accounting and companies (1) - Intermediate Accounting and companies (2) - Advanced Accounting.

- Accounting theory and international standards: Financial Statement Analysis - International Accounting Standards - accounting theory - International Accounting.

- Management Accounting and auditing: Management Accounting - Cost Accounting - accounts auditing International Auditing Standards.

- Accounting systems: accounting information systems - Tax Accounting - Governmental Accounting - Banks and insurance accounting.

Second:

Determine the general educational objectives required to be achieved in the specialty of accounting in general, which has been relied upon by (American Institute of Certified Public Accountants [AICPA], 1999) and its amendments. The Core Competencies Framework, as a general framework of the basic skills (competencies-qualifications) that was issued "Which frames the educational objectives of the accounting specialization and must be achieved at a minimum, those skills were classified into three main types:

1. Functional skills (competencies - qualifications).

2. Personal skills (competencies - Qualifications).

3. Large administrative perspective skills (competencies - qualifications) broad business perspective.

This study focused on accounting subjects, in particular, functional Competencies have been adopted which have been identified by the (AICPA) in following educational objectives:

i. Decision Modeling: (studying the company - identifying alternatives - selecting and applying solutions).

ii. Risk Analysis: (understanding the risks of auditing and the risks of the project).

iii. Measurement: (knowing the appropriate means to measure the performance and standards application).

iv. Reporting: (preparing accounting reports and reports on the work accomplished and results).

v. Research: (the ability to obtain the appropriate information to understand and apply that information).

vi. Leverage of technology to develop and enhance functional competencies: (use of information tec hnology for the development of the previous functional competencies).

\subsection{Measures and Covariates}

The questionnaire consisted of two parts:

i. Demographic variables include qualification, professional, and years of experience, gender and age.

ii. Second part Included 51 questions about the appropriate use of MCQs, in both theoretical and practical aspects, the questions have been ordered randomly, therefore the respondents options could be more neutral and objective.

a. Multiple choice questions, which are related to the achievement of educational objectives of accounting 
subjects concerning theoretical aspect, had the following numbers:

1-2-7-10-16-19-21-23-25-34-35-36-37-38-39-40-41-45-46

b. Multiple choice questions, which are related to the achievement of the educational objectives accounting subjects concerning practical aspect,(Recording, Posting, Journalize adjusting entries, Preparing financial statements, financial equations, Managerial equations, quantitative technique analysis and using computerized accounting Software) had the following numbers:

3-4-5-6-8-9-11-12-13-14-15-17-18-20-22-24-26-27-28-29-30-31-32-33-42- 43-44-47-48-49-50-51.

\subsection{Population and Sample of the Study}

Study population consists of faculty members working at accounting departments at Jordanian universities, sample has been selected randomly from the study population, where part of the questionnaire was distributed to respondents directly and the other part was distributed to respondents through E-mails, the total number of distributed questionnaires was 85 , and $\mathbf{6 2}$ questionnaires were returned and valid for the study analysis.

\subsection{Validity and Reliability}

Face validity was verified by a number of arbitrators of faculty member in Jordanian universities, questionnaire has been amended in light of their proposals, Cronbach Alpha was used to measure the reliabilityof study tool and the internal consistency of all questionnaire paragraphs, Cronbach Alphawas 95.5\% which is sufficient for the purposes to test the reliability of study tool, which was very high and acceptable, while research results can be reliable when Cronbach Alpha is more than $60 \%$.

\section{Statistical Anal ysis and Testing Resul ts}

\subsection{Distribution of the Study Variables}

This study investigates the suitability of MCQs to evaluate the educational process of accounting subjects. The research instrument addresses the theoretical as well as the practical aspects of accounting subjects. Each of the theoretical and the practical aspect was treated as separate variable and the indi vidual responses of each respondent to the items making up each of these two aspects of teaching were summed for each variable separately and the obtained sums, or totals, were tested for normality of distribution of the data using the Kolmogorov-Smirnov and the Shapiro-Wilk's tests at the 0.05 level of significance $(\alpha=.05)$. The same procedure was followed in the case of the sum of responses to the theoretical plus the practical facets of teaching 'Overall total score', which defines a measure of the overall aspects of the academic accounting teaching (referred to hereafter as the 'overall measure'. Since the sample size is less than $2000(N=62)$, the researchers used the results of the Shapiro-Wilk's test of normality. Outputs of test for normality (Table 1) illustrate what follows:

i. Table 1 reveals that the total score of the theoretical aspect of MCQs has normal distribution. Since $p=0.060>$ $\alpha=0.05$, the null hypothesis, which states that the population is normally distributed, cannot be rejected. However, the histogram reveals that distribution of this variable differs from the normal distribution. This result is supported by the skewness and kurtosis values (Table 2), which are both different, and somewhat far, from zero.

ii. Table 3 uncovers that the total score of the practical aspects of MCQs do not have normal distribution. The associated probability is less than $0.05(p=0.035<\alpha=0.05)$. Therefore, the null hypothesis is rejected. This result is augmented by the histogram as well as by the skewness and kurtosis values (Table 2), which both differ from zero.

iii. Table 4 shows that the total score for the sum of the practical and theoretical aspects of MCQs have a normal distribution as the associated probability is higher than the level of significance $(p=0.172>\alpha=0.05)$. Accordingly, the null hypothesis accepted. This finding is reinforced by the fact that the skewness and kurtosis values are both different from zero (Table 2).

Based on the foregoing points, it is concluded that none of the three study variables has normal distribution. 
Table 1. Test of distribution of MCQs for theoretical aspect

\begin{tabular}{lcccccc}
\hline \multirow{2}{*}{ Tested Variable } & \multicolumn{3}{c}{ Kolmogorov-Smirnov $^{\mathrm{a}}$} & \multicolumn{3}{c}{ Shapiro-Wilk } \\
\cline { 2 - 6 } Th-Tot & Statistic & $\mathrm{df}$ & Sig. & Statistic & df & Sig. \\
Th-Tot-Inv & .081 & 62 & $.200^{*}$ & .963 & 62 & .060 \\
Th-Tot-SqRt & .146 & 62 & .002 & .812 & 62 & .000 \\
Th-Tot-SqRtInvs & .096 & 62 & $.200^{*}$ & .941 & 62 & .005 \\
Th-Tot-Quad & .130 & 62 & .011 & .866 & 62 & .000 \\
Th-Tot-QuadInvs & .063 & 62 & $.200^{*}$ & .981 & 62 & .457 \\
Th-Tot-Log & .190 & 62 & .000 & .683 & 62 & .000 \\
Th-Tot-Ln & .112 & 62 & .051 & .909 & 62 & .000 \\
Th-Tot-ZScr & .112 & 62 & .051 & .909 & 62 & .000 \\
\hline
\end{tabular}

a. Lilliefors Significance Correction

*. This is a lower bound of the true significance.

Table 2. Descriptive Statistics of the theoretical, practical, and overall aspects of the academic

\begin{tabular}{lccc}
\hline Accounting Subjects & Th-Tot & Pr-Tot & Thr-Pr-Tot \\
\hline $\mathrm{N} \quad$ Valid & 62 & 62 & 0 \\
\multicolumn{1}{c}{ Missing } & 0 & 0 & 159.37 \\
Mean & 74.53 & 84.84 & 4.269 \\
Std. Error of Mean & 1.479 & 3.357 & 154.00 \\
Median & 76.00 & 83.00 & $130^{\mathrm{a}}$ \\
Mode & $76^{\mathrm{a}}$ & $64^{\mathrm{a}}$ & 33.612 \\
Std. Deviation & 11.642 & 26.429 & 1129.745 \\
Variance & 135.532 & 698.498 & .362 \\
Skewness & -.637 & .603 & -.190 \\
Kurtosis & .757 & -.057 & 159 \\
Range & 57 & 119 & 96 \\
Minimum & 38 & 41 & 255 \\
Maximum & 95 & 160 & 9881 \\
Sum & 4621 & 5260 & \\
\hline
\end{tabular}

a. Multiple modes exist. The smallest value is shown

Table 3. Tests of distribution of MCQs for practical aspect

\begin{tabular}{lcccccc}
\hline & \multicolumn{3}{c}{ Kolmogorov-Smirnov $^{\mathrm{a}}$} & \multicolumn{3}{c}{ Shapiro-Wilk } \\
\cline { 2 - 7 } Tested Variable & Statistic & $\mathrm{df}$ & Sig. & Statistic & df & Sig. \\
\hline Pr-Tot & .116 & 62 & .037 & .958 & 62 & .035 \\
Pr-Tot-Inv & .127 & 62 & .014 & .956 & 62 & .027 \\
Pr-Tot-SqRt & .102 & 62 & .179 & .976 & 62 & .269 \\
Pr-Tot-SqRtInvs & .109 & 62 & .067 & .975 & 62 & .229 \\
Pr-Tot-Quad & .129 & 62 & .012 & .889 & 62 & .000 \\
Pr-Tot-QuadInvs & .156 & 62 & .001 & .890 & 62 & .000 \\
Pr-Tot-Log & .088 & 62 & $.200^{*}$ & .982 & 62 & .476 \\
Pr-Tot-Ln & .088 & 62 & $.200^{*}$ & .982 & 62 & .476 \\
Pr-Tot-ZScr & .116 & 62 & .037 & .958 & 62 & .035 \\
\hline
\end{tabular}

a. Lilliefors Significance Correction

*. This is a lower bound of the true significance. 
Table 4. Tests of distribution of the overall aspects theoretical, practical, and overall aspects of accounting subjects

\begin{tabular}{lcccccc}
\hline & \multicolumn{3}{c}{ Kolmogorov-Smirnov $^{\mathrm{a}}$} & \multicolumn{3}{c}{ Shapiro-Wilk } \\
\cline { 2 - 7 } \multicolumn{1}{c}{ Tested Variable } & Statistic & df & Sig. & Statistic & df & Sig. \\
\hline Thr-Pr-Tot & .097 & 62 & $.200^{*}$ & .972 & 62 & .172 \\
ThrPr-Tot-Inv & .134 & 62 & .008 & .957 & 62 & .031 \\
ThrPr-Tot-SqRt & .110 & 62 & .059 & .979 & 62 & .382 \\
ThrPr-Tot-SqRtInvs & .128 & 62 & .013 & .972 & 62 & .167 \\
ThrPr-Tot-Quad & .124 & 62 & .018 & .937 & 62 & .003 \\
ThrPr-Tot-QuadInvs & .137 & 62 & .006 & .909 & 62 & .000 \\
ThrPr-Tot-Log & .121 & 62 & .025 & .979 & 62 & .380 \\
ThrPr-Tot-Ln & .121 & 62 & .025 & .979 & 62 & .380 \\
ThrPr-Tot-ZScr & .097 & 62 & $.200^{*}$ & .972 & 62 & .172 \\
\hline
\end{tabular}

a. Lilliefors Significance Correction

*. This is a lower bound of the true significance.

In view of the foregoing findings, the researchers attempted to normalize the data through standardization to the z-scale and seven Box-Cox transformations (inverse; square root; inverse square root; square; inverse square; log base $e(\ln )$; and $\log$ base $10(\log )$ transformations) and another run of the normality test was implemented. The results (Tables 1,3, and 4) point out that at least standardization and/or one transformation could normalize the aforementioned variables but neither standardization, nor a single transformation, led to normalization of all three variables. Based upon this result, the researchers will employ non-parametric, rather than parametric, statistical techniques (e.g., the Wilcoxon Signed-Rank (One-Sample) Test and the Mann-Whitney $U$ Test) in data processes and hypothesis testing.

\subsection{Hypotheses Testing}

The outputs of the normality test (Tables 1,3 , and 4 and Figures 1-6) illustrated that no study variable has normal distribution and that neither standardization, nor a single transformation, led to normalization of all three variables (Tables 1, 3, and 4). In consequence, researchers resorted to non-parametric, rather than to parametric, statistical techniques. In this regard, the first three null hypotheses were tested using the Wilcoxon Signed-Rank Test while the forth hypothesis was tested by the Mann-Whitney $U$ Test.

\section{Testing the First Hypothesis}

H01: Multiple-choice questions do not significantly ensure to achieve the educational objectives of accounting subjects in general, both practical and theoretical aspects.

A one-sample sign test, or a Kolmogorov-Smirnov test, or aWilcoxon Signed-Rank (One-Sample) test can be used. Subsequently, soundness of this null hypothesis was examined by means of the Wilcoxon Signed-Rank test, which is the non-parametric equivalent for the one-sample $t$-test, using the Minitab Software, v. 16.2 (Minitab Inc.). This test evaluates whether the population medians on certain dependent variable are comparable, or not, with a test value, i.e., if the median value of the target variable is different from a hypothesized value.

The research instrument has 51 items related to the theoretical and practical aspects of accounting subjects, with five choices (i.e., levels of agreement) for each. Weighing of the item scores followed a normal, five-point Likert scale where the highest level of agreement with suitability of the given item for achievement of the teaching goals was assigned the highest weight, and vice versa. Therefore, the lowest probable weight for any respondent, corresponding to that the multiple choice questions are not appropriate for achieving the goals of theoretical and practical subjects of accounting, is 51 (51 Items x 1). Meantime, the highest likely weight, indicating marked suitability of the multiple choice questions for achievement of the goals of theoretical and practical of teaching of the accounting courses, is 255 (51 Items x 5). Bearing in mind that the level of agreement indicated by 3 is the medium and median level of agreement on the scale for every item, then, the overall median is 153 (51 Items $x 3$ ). This value strikes the divide line between disagreement and agreement. Subsequently, in order to test the aforementioned hypothesis taking this median of the total score (153) as the hypothesized value for the median. If the median score of the sample faculty members is equal to, or significantly less than, 153.0, then the multiple choice questions are not relevant for achievement of the educational objectives of theoretical and practical teaching of the accounting courses, and vice versa. As Table 2 shows, the total score of the theoretical plus the practical items has a median of 154.0. 
In this case, in order to tests whether the sample median of 154 is statistically different enough from 153 at $a=$ 0.05 . The outputs of the Wilcoxon Signed-Rank (One-Sample) test, which are presented in Table 5, disclose that the estimated median score of the sample faculty members is 159.5 . In addition, the probability value $(p)$ is greater than the level of significance ((Wilcoxon test statistic $=1050.0, N^{*}=1, p=.901>.05=\alpha, N=62$ ). Since $p>\alpha$, we fail to reject the null hypothesis $\left(\mathrm{H1}_{0}\right)$ and thus reach to the conclusion that the sample median is not significantly different from 153 .

Table 5. Outcomes of the Wilcoxon Signed-Rank Test of the first hypothesis

Test of median $=153.0$ versus median $<153.0$

\begin{tabular}{lrrrrrr}
\hline Variable & $N$ & $N^{*}$ & N for Test & Wilcoxon Statistic & $p^{1}$ & Estimated Median \\
\hline Thr-Pr--Tot & 62 & 1 & 62 & 1159.5 & 0.901 & 159.5 \\
\hline
\end{tabular}

1: The level of significance $(\alpha)$ was set at .05 .

Since the Wilxoxon signed-rank test uncovered that the sample median (154) is not statistically significantly different from the hypothesized value (153), and then it is not greater than it. This implies that $\mathrm{H}_{0}$ is accepted because it can be accepted only when the sample median is significantly higher than the hypothesized value. In other words, the study data provide adequate evidence on that the sample university faculty members agree with that the MCQs cannot significantly ensure achieving the educational objectives of theoretical and practical aspects of accounting subjects.

\section{Testing the Second Hypothesis}

H02: Multiple-choice questions do not significantly ensure to achieve the educational objectives of accounting subjects, theoretical aspect.

In the case of the goals of theoretical teaching of the accounting subjects, the research instrument included 19 items. Hence, the lowest potential weight for any respondent, implying that the MCQs are not relevant for achievement of the goals of theoretical subjects ofaccounting, is 19 (19 Items x 1) while the highest probable weight, corresponding to appropriateness of the MCQs for achievement of the goals of theoretical teaching of the accounting subjects, is 95 ( 19 Items $\times 5$ ). Considering that the level of agreement indicated by 3 is the divide line between agreement and disagreement with every item, then the overall median is 57 (19 Items x 3). This value separates the agreement from the disagreement scores of the sample faculty member with suitability of the MCQs for realization of the goals of theoretical subjects of accounting. In consequence, the researcher tested the abovementioned hypothesis taking this median total score (57) as the hypothesized value. If the median score of the sample faculty members are equal to, or significantly less than, 57.0, then the multiple choice questions are not proper for the purpose of achieving the goals of theoretical teaching of the accounting subjects, and vice versa. The respondents' total score on the theoretical items has a median of 76.0 (Table 2).

To determine if the median value of the target variable is different from the hypothesized value (57), the researchers examined soundness of the foregoing null hypothesis $\left(\mathrm{H} 2_{0}\right)$ using the Wilcoxon Signed-Rank test and the Minitab Software, v. 16.2 (Minitab Inc.)

The outcomes of the Wilcoxon signed-rank test (Table 6) reveal that the estimated median score of the sample faculty members is 75.00. In addition, the probability value $(p)$ is higher than the level of significance ( (Wilcoxon test statistic $\left.=1896.5, N^{*}=1, p=1.000>.05=\alpha, N=62\right)$. As $p>\alpha$, the researchers fail to reject the null hypothesis and thus reaches to the conclusion that the sample median is not significantly different from 57.

Table 6.Outcomes of the Wilcoxon Signed-Rank Test of second hypothesis

Test of median $=57.00$ versus median $<57.00$

\begin{tabular}{|c|c|c|c|c|c|c|}
\hline Variable & $N$ & $N^{*}$ & $\mathrm{~N}$ for Test & Wilcoxon Statistic & $p^{1}$ & Estimated Median \\
\hline Thr-Pr--Tot & 62 & 1 & 62 & 1896.5 & 1.000 & 75.00 \\
\hline
\end{tabular}

1: The level of significance $(\alpha)$ was set at .05 .

As to that the Wilxoxon signed-rank test disclosed that the sample median (76) is not statistically significantly different from the hypothesized value (153), and then it is not greater than it. What this means is that $\mathrm{H} 2{ }_{0}$ is accepted because it can be accepted only when the sample median is significantly greater than the hypothesized value. That is, the sample data provide enough evidence on that, from the point view of the sample university faculty members, the MCQs cannot significantly ensure achieving the educational objectives of theoretical aspects of accounting subjects. 


\section{Testing the Third Hypothesis}

H03: Multiple-choice questions do not significantly ensure to achieve the educational objectives of accounting subjects, practical aspect.

As regards the goals of practical teaching of the accounting subjects, the research instrument included 32 items. Consequently, the lowest likely score for any respondent, revealing that the MCQs are not suitable for achieving the goals of practical subjects of accounting, is 32 (32 Items x 1) whereas the highest potential score, corresponding to appropriateness of the MCQs for achievement of the goals of practical teaching of the accounting subjects, is 160 ( 32 Items $x$ ). Taking the level of agreement indicated by 3 as the cut point between disagreement and agreement with every item, then the overall median is 96 ( 32 Items $x 3$ ). This value is the cut point between agreement and disagreement of the sample university faculty member with relevance of the MCQs for achievement of the goals of practical subjects of accounting. Therefore, the researcher tested the abovementioned hypothesis taking this median total score (96) as the hypothesized value. If the median score of the sample faculty members is equal to, or significantly less than, 96.0, then the MCQs are not suitable for achievement of the goals of practical teaching of the accounting subjects, and vice versa. The respondents' total score on the theoretical items has a median of 83.0 (Table 2).

So as to specify if the median value of the target variable (83) is different from the hypothesized value (96), the researcher examined soundness of the foregoing null hypothesis $\left(\mathrm{H}_{0}\right)$ following the Wilcoxon Signed-Rank test and using the Minitab Software, v. 16.2 (Minitab Inc)

The Wilcoxon signed-rank test shows that the estimated median score of the sample faculty members is 83.00 (Table 7). Furthermore, this test uncovers that the probability value $(p)$ is less than the level of significance (Wilcoxon test statistic $=506.5, N^{*}=1, p=.001>.05=\alpha, N=62$ ). As $p<\alpha$, the researcher rejects the null hypothesis in favor of the alternative hypothesis and concludes that the sample median is significantly less than 96.

Table 7. Outcomes of the Wilcoxon Signed-Rank Test of third hypothesis

Test of median $=96.00$ versus median $<96.00$

\begin{tabular}{|c|c|c|c|c|c|c|}
\hline Variable & $N$ & $N^{*}$ & $\mathrm{~N}$ for Test & Wilcoxon Statistic & $p^{1}$ & Estimated Median \\
\hline Thr-Pr--Tot & 62 & 1 & 61 & 506.5 & .001 & 83.00 \\
\hline
\end{tabular}

1: The level of significance $(\alpha)$ was set at 05 .

The Wilxoxon signed-rank test brings to notice that the sample median (83) is statistically significantly less than the hypothesized value (96). This implies that $\mathrm{H}_{3}$ is accepted due to that it can only be accepted if the sample median is significantly higher than the hypothesized value. Thereupon, the sample data provide sufficient evidence to conclude that, from the standpoint of the sample university faculty members, the multiple-choice questions can not significantly ensure achieving the educational objectives of practical aspects of the accounting subjects.

\section{Testing the Fourth Hypothesis}

H04: There are no statistically-significant differences between the faculty members of private and public universities in their assessment of suitability of multiple-choice questions to achieve the educational objectives of accounting subjects, theoretical and practical aspects.

The potential statistically-significant $(\alpha=0.05$ ) difference between the sample faculty members of the private and the public universities in their assessment of the relevance of the MCQs for achievement of the goals of the theoretical plus the practical subjects of accounting. Since the number of groups under consideration is two, then the researcher conducted the Mann-Whitney $U$ test, which is the non-parametric equivalent of the twoindependent sample $t$-test.

The test results (Table 8) demonstrate that no statistically-significant difference exists between the sample private and public university faculty members (Mann-Whitney $U=380.500, p$ (Asymp. Sig. (2-tailed) $)=.275$ $>\alpha=.05$ ). As the mean ranks output of this test shows, the public university faculty members have only slightly higher mean rank of the total score on the instrument's 51 items than the private university faculty members (34.65 against 29.51). In light of these findings, the researcher accepts the foregoing research hypothesis and concludes that there is no statistically-significant $(\alpha=0.05)$ difference between the faculty members of the private and public universities in their perceptions of suitability of the MCQs for achievement of educational objectives of the theoretical plus practical academic subjects of accounting. 
Table 8. Pairwise comparisons between the private and public university faculty members in perception of the ability of the MCQs to achieve the educational objectives of accounting subjects

\begin{tabular}{|c|c|c|}
\hline Test statistics ${ }^{a, b}$ & & \\
\hline Mann-Whitney U & 380.500 & \\
\hline Wilcoxon W & 1121.500 & \\
\hline Z & -1.091 & \\
\hline Asymp. Sig. (2-tailed) & .275 & \\
\hline Ranks & & \\
\hline Descriptive & Private & Public \\
\hline$N$ & 38 & 24 \\
\hline Mean Rank & 29.51 & 34.65 \\
\hline Sum of Ranks & 1121.50 & 831.50 \\
\hline
\end{tabular}

a. Grouping Variable: University

b. $N=62$

Frequency Distribution Analysis

In order to identify the aspects of accounting teaching, both theoretical and practical, which the sample faculty members support that the MCQs do achieve the accounting teaching goals through them and those which do not. To this end, the researchers subjected the 51 instrument items to frequency distribution analysis (Table 9).

First

The largest proportion of the sample university faculty members strongly agreed on that the multiple choice questions are suitable for evaluation the achievement of the educational objectives of accounting subjects in eight aspects. In descending order, these are (Table 9):

1. Differentiating between the types of auditing. (61.3\% (Theoretical Aspect)).Furthermore, no one of the sample university faculty members disagreed strongly with this issue.

2. Defining the internal control system and its elements. (59.7\% (Theoretical aspect)).

3. Differentiating between the auditing report types and when each type of reports should be prepared. (58.1\%(Theoretical aspect)).In addition, no single faculty member strongly disagreed with this aspect.

4. Remembering auditing standards (GAAS). (56.5\% (Theoretical aspect)).Moreover, no one of the sample members disagreed strongly this point.

5. Knowing the fundamental concepts of financial accounting (hypotheses; international accounting standards; professional ethics). (53.1\% (Theoretical aspect)). Meantime, no sample member disagreed strongly with this aspect.

6. Knowing and understanding the audit risks. (51.6\% (Theoretical aspect)).

7. Determining and understanding the stages of the auditing process (planning, applying, etc). (50.0\% (Theoretical aspect))

8. Differentiating between the different costs concepts (48.4\% (Theoretical aspect)).Meanwhile, no single sample member disagreed strongly with this issue.

Second

Alarge number of the sample university faculty members agreed on that the MCQs are suitable for evaluation the achievement of the educational objectives of accounting subjects in five aspects. In descending order, these are (Table 9)

1. Ability to recall and distinguish the basic factors of leas accounting contracts and operational contracts according to the International Accounting Standards. (58.1\% (Theoretical aspect)).

2. Determining the tax exemptions for the individuals and the companies (56.5\% (Theoretical aspect)).

3. Distinguishing between the adjustments of accounting policies, adjustments of accounting estimates and corrections of the accounting errors. (54.8\% (Theoretical aspect)). 
4. Being able to specify and classify types of risks whichcompanies may confront in future.(53.2\%(Theoretical aspect)).

5. Being able to interpret and justify the management's decision in the differentiation between the different accounting methods (e.g., selection of Accelerateddepreciation method over the Straight line method).

(51.6\% (Theoretical aspect)).

Interestingly, all foregoing 12 aspects belong to the theoretical facet of the accounting academic teaching.

Third

Almost half of number of the sample university faculty members strongly disagreed with that the MCQs are suitable for evaluation the achievement of the educational objectives of accounting subjects in three aspects, implying that this type of questions is not suitable for achievement of accounting teaching goals. These aspects are (Table 9):

1. Ability to prepare all types of financial statements. (54.8\% (Practical Aspect)).

2. Using other necessary technological skills which are useful in current working environment (WinWord, PowerPoint, etc.). (50.0\% (Practical Aspect)).

3. Using the computer to prepare a database (Access). (48.4\% (Practical Aspect)).

\section{Fourth}

About half of the sample university faculty members disagreed with that the MCQs are suitable for evaluation the achievement of the educational objectives of accounting subjects in four aspects, implying that this type of questions is not suitable for achievement of the accounting teaching goals. These aspects are (Table 9):

1. Expressing opinion about the company's actual performance and make comparison between budgets and actual results. (50.0\% (Practical Aspect)).

2. Being able to measure the standard deviations and prepare performance reports.(48.4\% (Practical Aspect)).

3. Preparing tax declaration for the individuals and companies. (48.4\% (Practical Aspect)).

Fifth

For all the 51 examined issues, the proportions of the sample university faculty members who did not know the suitability of MCQs for the achievement of the educational objectives of accounting subjects were very low (Table 9), much less than 10.0\%, except in one case (Using computer software for enterprise resource planning (ERP). (11.3\%). This is much expected knowing that the sample members are all specialized and highlyqualified academics, who, additionally, have generally appreciable experience in teaching accounting subjects.

Table 9. Items frequency distribution analysis

\begin{tabular}{|c|c|c|c|c|}
\hline Level of Agreement ${ }^{\text {a, b }}$ & & & & \\
\hline Statement & 1 & 2 & 3 & 4 \\
\hline 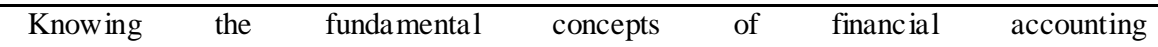 & & & & \\
\hline 1 (hypotheses; international accounting standards; professional ethics). & 0.0 & 9.7 & 0.0 & 32.353 .1 \\
\hline $\begin{array}{l}\text { Recalling basic steps of accounting cycle (analysis the recording process, journalising } \\
2 \text { and balancing the accounts and posting to the Ledger; preparing trail balance). }\end{array}$ & 32.3 & 38.7 & 1.6 & 19.48 .1 \\
\hline $\begin{array}{l}\text { Applying the steps of accounting cycle (analys is the recording process, journalizing and } \\
3 \text { balancing the accounts and posting to the Ledger; preparing trail balance). }\end{array}$ & 38.7 & 38.7 & 1.6 & 14.56 .5 \\
\hline $\begin{array}{l}\text { Applying types of depreciations of fixed assets and ability to make comparison between } \\
\text { them. }\end{array}$ & 17.7 & 36.5 & 3.2 & 37.16 .5 \\
\hline 5 Knowing how to record the adjusting entries. & 30.6 & 38.7 & 1.6 & 21.08 .1 \\
\hline 6 Ability to prepare all types of financial statements. & 54.8 & 25.8 & 3.2 & 11.34 .8 \\
\hline $\begin{array}{l}\text { Ability to recall and distinguish the basic factors of leas accounting contracts and } \\
7 \text { operational contracts according to the International Accounting Standards. }\end{array}$ & 1.6 & 17.7 & 6.5 & 58.116 .1 \\
\hline
\end{tabular}


Identify the recording processing of the leas accounting contracts and financial operation

${ }_{10}$ Distinguishing between the adjustments of accounting policies, adjustments of accounting estimates and corrections of the accounting errors.

Knowing way of adjustments accounting policies and adjustments of accounting

11 estimates and corrections of the accounting errors.

Knowing how to present and disclose the adjustments in accounting methods,

14Using ready accounting software for applying the whole accounting cycle

15 Using the computer (Excel program) in calculating the depreciations.

Being able to interpret and justify the management's decision in the differentiation 16 between the different accounting methods

16 (e.g., selection of Accelerateddepreciation method over the Straight line method).

Being able to study and analyze the financial situation of the company and to compare it

17 other companies in the same segment.

Being able to give opinion on a certain case study through selection and application of a 18 suitable solution for financial problems that the company faces (e.g., internal or external financing).

${ }_{19}$ Being able to specify and classify types of risks whichcompanies may confront in future.

Being able to analyze and understand the project risks concept through the use of the 20 financial analysis tools.

$\begin{array}{llll}1.6 & 11.3 & 6.5 & 53.227 .4 \\ 9.7 & 40.3 & 0.0 & 40.39 .7\end{array}$

Ability to understand and explain the disadvantages and advantages of each accounting 21 process.

${ }_{25}$ Understanding the advantages and disadvantages of manufacturing overheads cost 25 distribution methods (ABC).

Being able to analyze the relationships between the cost, volume of sales, and profit 26 (C-V-P).

Being able to analysis the break-even point for the project and prepare the income 31 statement.

Expressing opinion about the company's actual performance and make comparison 32 between budgets and actual results.

(1.

Using the computer in preparing discretionary budgets and analyzing the standard 33 deviations. 
34Knowing and understanding the audit risks.

\begin{tabular}{cccc}
1.6 & 11.3 & 4.8 & 30.651 .6 \\
0.0 & 3.2 & 3.2 & 37.156 .5 \\
1.6 & 6.5 & 3.2 & 29.059 .7 \\
1.6 & 9.7 & 6.5 & 32.350 .0 \\
0.0 & 1.6 & 1.6 & 35.561 .3 \\
0.0 & 3.2 & 4.8 & 33.958 .1 \\
0.0 & 12.9 & 8.1 & 56.522 .6 \\
0.0 & 9.7 & 6.5 & 43.540 .3 \\
17.7 & 48.4 & 6.5 & 22.64 .8 \\
38.7 & 37.1 & 6.5 & 11.36 .5 \\
8.1 & 30.6 & 9.7 & 37.114 .5 \\
& & & \\
3.2 & 29.0 & 4.8 & 43.519 .4 \\
0.0 & 22.6 & 3.2 & 38.735 .5 \\
37.1 & 40.3 & 6.5 & 11.34 .8 \\
48.4 & 30.6 & 6.5 & 6.58 .1 \\
30.6 & 35.5 & 11.3 & 9.712 .9 \\
\hline 50.0 & 25.8 & 3.2 & 12.98 .1
\end{tabular}

35Remembering auditing standards (GAAS).

36 Defining the internal control system and its elements.

Determining and understanding the stages of the auditing process (planning, applying, 37 etc).

38 Differentiating between the types of auditing .

${ }_{39}$ Differentiating between the auditing report types and when each type of reports should be 39 prepared.

${ }_{40}$ Determining the tax exemptions for the individuals and companies.

41Identifying the tax law for the individuals and companies.

42Preparing tax declaration for the individuals and companies.

43 Using the computer in preparation of tax declaration.

Knowing how to use the documentation methods (document flow maps/charts) and

44 evaluating the internal control system.

Knowing how to prevent and discover mistakes in operation of computerized information $45_{\text {system, fraud, and deception. }}$

${ }_{46}$ Knowing the internal control concepts which prevent the error before it occurs.

${ }_{47}$ Using the computer in developing electronic tables (Excel).

${ }_{48}$ Using the computer to prepare a database (Access).

49 Using computer software for enterprise resource planning (ERP).

50 environment (WinWord, PowerPoint, etc.).

Studying practical cases to show how the companies can benefit from tax exemptions and 51 the governmental concessions(site, specialization, etc.).

\section{Results and Recommendations}

\subsection{Results}

In light of data analysis and hypotheses testing, it's obvious that faculty members in universities use MCQs as a tool to assess the deep understanding and level of knowledge among students of accounting specialization exams. Analysis reveals that, sample university faculty members agree that the MCQs cannot significantly ensure the ability in achieving the educational objectives related to the theoretical and practical aspects in accounting subjects, furthermore there is no significant difference between the faculty members of private and public universities in their perceptions of non- suitability of MCQs in order to reach the goals of educational objectives.

Nonetheless, faculty members still use MCQs in exams of accounting subjects. In addition the Ministry of Higher Education focused on setting special instructions for knowledge field of accounting specialization in general but did not give enough concern about the educational objectives for each field, which usually covers the personal, functional and administrative aspects for the students in accounting specialization as in the case of the general framework of the basic skills (competencies-qualifications).

\subsection{Recommendations}

Its recommended that there is need to re-consider the necessity to use essay questions in university exams in order to test students' practical abilities regarding accounting specialization, which is considered as the best of all to assess the cognitive level of student understanding and In-depth learning, furthermore, to insure measurement of comprehension, analysis, structure and assembly, especially the purpose of evaluation process in respect to test the student ability to reach to the correct information.

MCQs may be used in university exams to test the student's theoretical and practical abilities and to evaluate the general matters related to educational subject, taking into consideration the following points when using this type of questions to get the best results:

1. Questions should be prepared in a precisely, carefully and pretested manner, 
2. Questions should be built serially and identically according to the sequence of educational subject that has been taught to cover a wider range of educational subject in order to help students to call memory and restore the information.

3. Questions should be started typically with the easiest questions then to be stepped gradually to the most difficult in order to build the self-confidence for the student.

4. Preparation of different models to reduce deceiving attempts, whether by using different questions or by using a different order of questions in each model.

5. Building a question bank of multiple-choice questions for each educational subject.

6. The Ministry of Higher Education in Jordan has to be guided by the general framework of basic skills and develop a special instructions with regards to accounting specialization to include a special educational objectives, which covers the personal, functional and administrative side for the accounting students as well as the field of cognitive side which is allocated generally to accounting specialization.

7. The need to generalize this study to include:

i. Learning and vocational training.

ii. Teaching in various stages, under graduation education and post graduation academic stages such as Master and $\mathrm{PhD}$.

iii. Non-accounting courses that are taught within the syllabus of accounting specialization.

\section{References}

Accreditation and Quality Assurance Commission for Higher Education Institutions [HEAC]. (2007).Amendment No. (2010/5/32) Date (18/2/2010). Retrieved from http://www.heac.org.jo

AICPA. (1999). Core Competency Framework \& Educational Competency Assessment, Retrieved fromhttp://www.aicpa.org

Ali, S. H., Carr, P. A., \& Ruit, K. G. (2016).Validity and Reliability of Scores Obtained on Multiple-ChoiceQuestions: Why Functioning Distractors Matter, Journal of the Scholarship of Teaching and Learning, 16(1), 1-14.https://doi.org/10.14434/josotl.v16i1.19106

Balch, W. R. (1989). Item order affects performance on multiple-choice exams. Teaching of psychology Journal, 16(2), 75-77. https://doi.org/10.1207/s15328023top1602_9

Bible, L., Simkin, M. G., \& Kuechler, W. L. (2007). Using of multiple-choice tests to evaluate students understanding of accounting, An International Journal, 17(1).

Bloom, B. E. (1964). Taxonomy of education objectives. New York: David McKay.

Bridgeman, Brent and Charles Lewis. (1994). The relationship of essay and multiple-choice scores with grades in college courses. Journal of Educational Measurement, 31(1), 37-50. https://doi.org/10.1111/j.1745-3984.1994.tb00433.x

Buckles, S., \& Siegfried, J. (2006).Using multiple-choice questions to evaluate in-depth learning of economics. The journal of Economic Education, 37(1), 48-57. https://doi.org/10.3200/JECE.37.1.48-57

Cronbach, L. (1970). Essentials of Psychology Testing.Harper \& Row, New York, USA.

Gul, F., Teoh, H. Y., \& Shannon, R. (1992). Cognitive style as a factor in accounting students performing on multiple choice examination. Accounting Education: An International Journal, 1(4), 311-319.https://doi.org/10.1080/09639289200000048

Hinton, P. R., Brownlow, C., McMurvay, I., \& Cozens, B. (2004). SPSS explained, East Sussex, England: Routledge Inc.

IAESB International Accounting Education Standards Board, IES 3, Professional Skills and General Education. (2011). http://www.ifac.org

Kaiser, H. F. (1960). The application of electronic computers to factor analysis.Educational and Psychological Measurement, 20(1), 141-151.https://doi.org/10.1177/001316446002000116

Kim, S., Spielberg, F., Mauksch, L., Farber, S., Duong, C., Fitch, W., \& Greer, T. (2009). Comparing narrative and multiple-choice formats in online communication skill assessment.Journal of Medical Education, 43(6), 533-541.https://doi.org/10.1111/j.1365-2923.2009.03368.x 
Kuechler, W. L., \&Simkin, M. G. (2003). How Well Do Multiple Choice Tests Evaluate Student Understanding in Computer Programming Classes. Journal of Information Systems Education, 14(4), 389-398.

Laffittee, R. G. (1984). Effective of item order on achievement test scores and students perceptions of test difficulty. Teaching of psychology Journal, 11(4), 212-214.https://doi.org/10.1177/009862838401100405

Stupans, I. (2006). Multiple choice questions: Can they examine application of knowledge. Journal of Pharmacy, 6(1), 59-63. https://doi.org/10.1080/15602210600567916

Tsui, J. S., Lau, T. S., \& Fong, S. C. (1995). Analysis of accounting students performance on multiple-choice examination questions: a cognitive style perspective. Journal of Accounting Education, 4(4), 351-357.https://doi.org/10.1080/09639289500000039

Witkin, H. A., Moor, C. A., Goodenough, D. R., \& Cox, P. W. (1977). Field dependent and field independent cognitive style and their educational implications, Review of Educational Research, 47, 1-64. https://doi.org/10.3102/00346543047001001

Zaytoun, H. H. (2001). Teaching design: A systematic vision. Egypt, World of Books.

Zucker, S. (2003). Assessment Report: Fundamentals of Standardized Testing, San Antonio, TX: Pearson.

\section{Copyrights}

Copyright for this article is retained by the author(s), with first publication rights granted to the journal.

This is an open-access article distributed under the terms and conditions of the Creative Commons Attribution license (http://creativecommons.org/licenses/by/4.0/). 